\title{
PENGARUH KEPEMIMPINAN, MOTIVASI, DAN KOMPETENSI TERHADAP KINERJA MELALUI KEPUASAN PADA GURU SMK MUHAMMADIYAH BULAKAMBA BREBES
}

\author{
Aly Murtadlo dan Tabrani \\ STAI Shalahuddin Al Ayyubi, dan Universitas Pancasakti Tegal \\ nailuhal@gmail.com
}

\begin{abstract}
The purpose of this research is 1) for described leadership, motivation, competence, satisfaction and performance of teachers 2) to analyze the influence of leadership, motivation, and competence to satisfaction teachers 3) to analyze the influence of leadership, motivation, and competence of the performance of teachers 4) to analyze the influence of satisfaction with performance of teachers 5) to analyze the influence of leadership, motivation, and competence of the performance of through satisfaction teachers. Respondents in this research as many as 38 people. These respondents teachers are smk muhammadiyah bulakamba brebes. This research using structural equation modeling (shem) run through amos 19 as a means of the analysis. The results of the analysis data prove that leadership, motivation, and competence influential in significant impact on satisfaction teachers as evidenced of the value of the regression coefficient terstandar (beta) as much as 0,56, motivation work against satisfaction work teachers have value of 0.24 and competence to satisfaction work teachers get value 0.19. Leadership, motivation, and competence influential in significant impact on performance of teachers who evidenced of the value of the regression coefficient terstandar (beta) leadership of the performance of teachers get value 0.12, motivation work of the performance of teachers get value by 0.39 and competence of the performance of teachers have value of 0,46. Satisfaction influential significantly of the performance of teachers. This is evidenced from the p-value very small $(<0,001)$. Leadership, motivation, and competence influential significantly on performance through satisfaction teachers as evidenced from the p-value sanggat small $(<0,00)$.
\end{abstract}

Keywords: style leadership, motivation, competence, satisfaction, performance

\section{PENDAHULUAN}

Proses pendidikan senantiasa menjadi bagian yang strategis dalam pencapaian kemajuan suatu bangsa. Maju mundurnya suatu bangsa sangat ditentukan oleh kualitas pendidikan bangsa ini. Maka dari itu indikator suatu bangsa sangat ditentukan oleh tingkat sumber daya manusianya, dan indikator sumber daya manusia ditentukan oleh tingkat pendidikan masyarakatnya. Semakin tinggi sumber daya manusia- nya, maka semakin baik tingkat pendidikannya, dan demikian pula sebaliknya semakin baik mutu pendidikan.

Bagi Indonesia, pendidikan merupakan aspek terpenting dalam pembangunan bangsa. Karena pendidikan menunjukkan kunci keberhasilan suatu negara untuk mampu bersaing dan memiliki sumber daya manusia yang berkualitas. Dengan demikian, seluruh 
sumber daya manusia harus mampu mengembangkan dirinya lebih lanjut untuk memaksimalkan kualitas diri dan potensi yang dimilikinya. Salah satu sumber daya manusia yang harus mengembangkan kualitas dan potensi diri adalah kepala sekolah.

Tinggi rendahnya motivasi kerja guru sangat berpengaruh terhadap kinerja yang dapat dicapai oleh seorang guru. Seorang guru dikatakan memiliki motivasi kerja yang tinggi apabila merasa puas terhadap pekerjaannya, memiliki motivasi dan rasa tanggung jawab dan disiplin sehingga pekerjaan dapat terlaksana dengan mudah dan dapat tercapai apa yang menjadi tujuannya.

Pada masa sekarang guru perlu melakukan beberapa usaha dalam membangun kompetensi. Pertama, guru harus memiliki rasa tidak puas dengan keadaan atau dengan apa yang telah diperoleh, terutama sekali dalam bidang usaha mengajar. Kedua, guru harus dapat memahami anak sebagai pribadi yang unik, yang satu sama lain memiliki kekuatan dan kecerdasannya masingmasing. Ketiga, sebagai guru dituntut untuk menjadi pribadi yang fleksibel dan terbuka. Fleksibel menghadapi situasi yang selalu maju dalam dunia pendidikan. Keempat, guru harus merasa terpanggil untuk menekuni profesinya sebagai guru (Listiyono, 2004).

Mengingat pentingnya peranan guru, maka kinerja guru harus selalu diawasi dan ditingkatkan. Pengawasan ini datangnya dari kepala sekolah dan pengawas yang ditunjuk untuk mengawasi jalannya realitas kinerja guru. Namun sayangnya, guru berusaha menampakkan kinerja mengajar terbaiknya pada saat kunjungan pengawas saja, sedangkan dalam realitas kesehariannya dengan peserta didik guru mengajar seadanya, tanpa persiapan yang matang, tanpa pelaksanaan pembelajaran yang mampu memotivasi peserta didik dan tanpa bersemangat tinggi.

Kinerja guru yang baik tidak terlepas dari peran kepemimpinan kepala sekolah sebagai pemicu peningkatan kompetensi, motivasi, dan kinerja guru itu sendiri. Sekolah yang efektif ditentukan oleh kepemimpinan kepala sekolah yang efektif pula yang handal dalam memimpin sekolahnya. Efektivitas mengajar guru akan optimal, jika kepala sekolah dapat mengatur dan membimbing guru-guru secara baik sehingga para guru dapat melaksanakan tugastugasnya dengan penuh tanggung jawab, memperhatikan kepentingan dan kesejahteraan bawahannya sehingga tidak ada keluhan dalam menjalankan tugas dan kewajiban sehari-hari, harus menunjukkan kewibawaannya sehari-hari, sehingga dapat diteladani dan dipatuhi oleh para guru maupun peserta didik. Menetapkan dan sekaligus melaksanakan peraturan-peraturan yang logis dan sistematis, dan dapat diterima oleh semua pihak yang terkait dalam peningkatan efektifitas mengajar guru.

Hasil observasi sementara yang dilakukan peneliti tampak terdapat beberapa guru belum menunjukkan kinerja baik dalam menjalankan tugas dan fungsinya, artinya sesuai dengan tugas pokok dan fungsi guru, seperti: kegiatan dalam merencanakan progam pengajaran, melaksanakan kegiatan pembelajaran, melaksanakan penilaian, melaksanakan ulangan harian, menyusun dan melaksanakan program perbaikan dan pengayaan serta mengadakan pengembangan bidang pengajaran yang menjadi tanggung jawabnya. Sebagai gambaran profil guru yang kinerjanya masih rendah, antara lain: guru mengajar secara monoton dan tanpa persiapan yang matang. Guru masih menggunakan persiapan mengajar dengan sangat sederhana, belum sepenuhnya menggunakan acuan kurikulum yang diper- 
syaratkan, dan tidak konsisten dalam implementasi skenario rencana pelaksanaan pembelajaran (RPP) yang telah dipersiapkan dan pada proses pembelajaran guru masih dominan menggunakan metode ceramah.

Kinerja penting untuk diteliti karena ukuran keberhasilan dari suatu organisasi atau sekolah dapat dilihat dari kinerja maupun pelaksanaan pekerjaannya sehingga kemajuan suatu sekolah dapat dipengaruhi oleh kinerja gurugurunya. Penilaian kinerja guru sebenarnya merupakan penilaian terhadap penampilan kerja guru itu sendiri terhadap taraf potensi kerja guru dalam upaya mengembangkan diri untuk kepentingan sekolah. Mengingat pentingnya masalah tersebut, dan untuk menyikapi kondisi tersebut diatas, maka dilakukan penelitian ini yang diharapkan dapat memberikan manfaat bagi organisasi dalam memberikan motivasi kepada guru sehingga tujuan organisasi dapat tercapai secara optimal.

Berdasarkan hal-hal yang telah diuraikan di atas, maka penulis sangat tertarik untuk mengkaji lebih lanjut permasalahan ini dalam bentuk penelitian dan mengambil judul. "Pengaruh Kepemimpinan, Motivasi dan Kompetensi terhadap Kinerja Melalui Kepuasan Pada Guru SMK Muhammadiyah Bulakamba Brebes".

\section{METODE}

Penelitian merupakan jenis penelitian deskriptif dengan pendekatan kuantitatif, sebab dalam penelitian ini data-datanya berupa angka yang akan dianalisis dengan menggunakan statistik. Dengan mengkaji fakta-fakta yang telah terjadi serta semua data dari informasi yang diwujudkan dalam bentuk angka. Sesuai dengan permasalahan yang akan diteliti, maka penelitian ini bersifat ex-post fakto, yaitu penelitian yang dilakukan untuk mengungkap data dari peristiwa-peristiwa yang telah terjadi atau karena menurut sifatnya tidak dapat dimanipulasi. Jadi dalam penelitian ini tidak menggunakan perlakuan terhadap variabel penelitian melainkan mengkaji fakta-fakta yang telah terjadi dan pernah dilakukan. Untuk mendapatkan Instrumen penelitian yang valid dan reliabel harus terlebih dahulu dilakukan uji coba instrument yakni uji validitas dan relaibilitas dengan menggunakan rumus Product Moment dan Alpha Cronbach. Sedangkan alat analisis data dan interpretasi untuk penelitian yang ditujukan untuk menjawab pertanyaan-pertanyaan penelitian dalam rangka mengungkap fenomena social tertentu, Metode yang dipilih untuk menganalisis data harus sesuai dengan pola penelitian dan variable yang akan diteliti. Untuk menganalisis data digunakan The Structural Equation Modeling (SEM) dari paket software statistik AMOS 19 dalam model dan pengkajian hipotesis. Model persamaan structural, Structural Equation Model (SEM) adalah sekumpulan teknik-teknik statistikal yang memungkinkan pengujian sebuah rangkaian hubungan relatif "rumit" secara simultan (Ferdinand, 2011). 


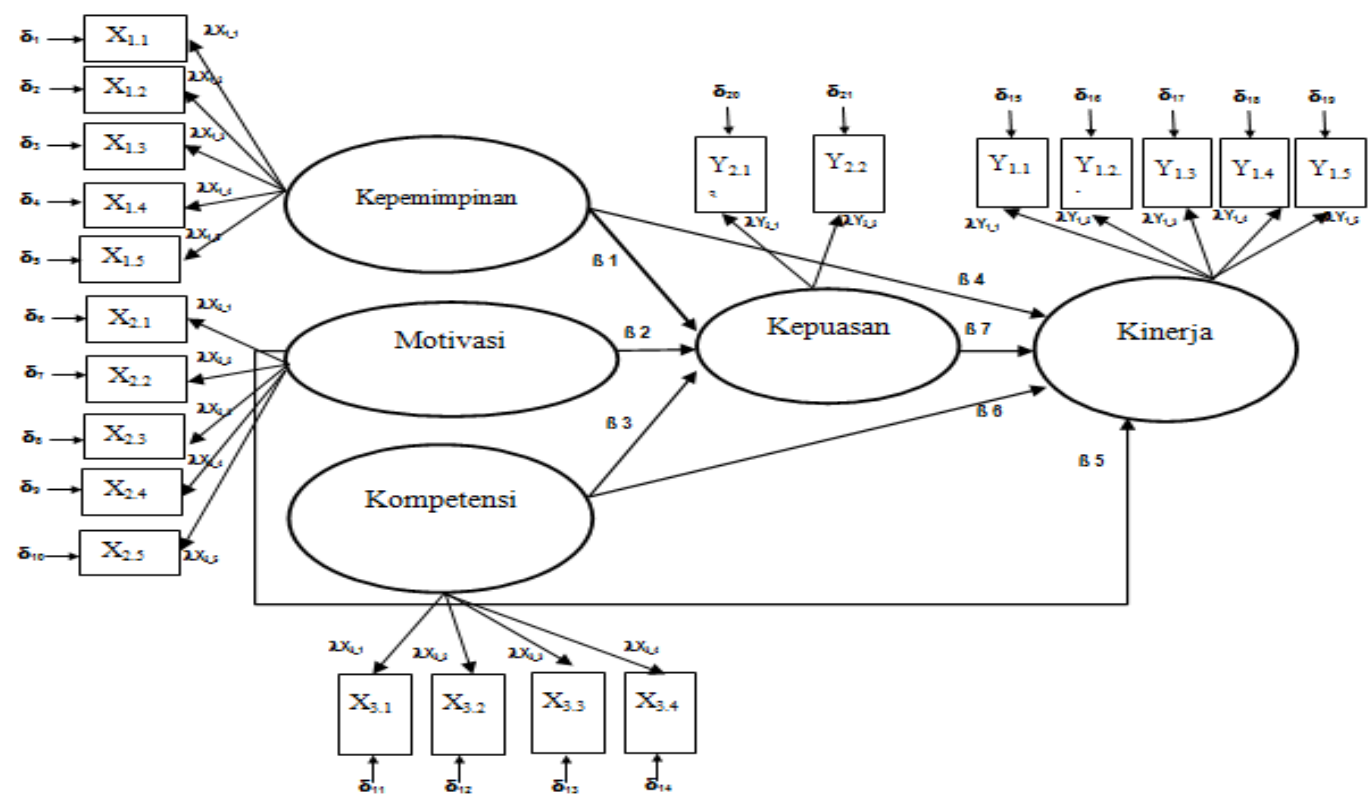

Gambar 1

Model Persamaan Struktural Penelitian

\section{HASIL DAN PEMBAHASAN}

\section{Analisis Asumsi Structural Equating Modeling (SEM)}

Untuk melakukan analisis inferensial dalam penelitian ini digunakan teknik Structural Equation Modeling (SEM). Dalam melakukan analisis dengan teknik Structural Equation Modeling (SEM), estimasi dilakukan secara bertahap, yaitu pertama, dengan melakukan teknik Confirmatory Factor Analysis. Analisis Faktor Konfirmatori (Confirmatory Factor Analysis) disebut sebagai teknik analisis faktor konfirmatori sebab pada tahap ini model akan mengkonfirmasi apakah variabel yang diamati dapat mencerminkan faktor yang dianalisis. Unidimensionalitas dari dimensi-dimensi itu diuji melalui confirmatory factor analysis yang hasilnya seperti yang disajikan berikut ini.

\section{a. Analisis Konfirmatori Variabel Kepemimpinan $\left(\mathbf{X}_{1}\right)$}

Analisis konfirmatori variabel kompetensi dilakukan untuk meng- konfirmasi apakah indikator yang diamati dapat mencerminkan faktor yang dianalisis yaitu variabel kepemimpinan. Adapun hasil analisis konfirmatori yang dilakukan terhadap variabel kepemimpinan diuraikan di bawah ini :

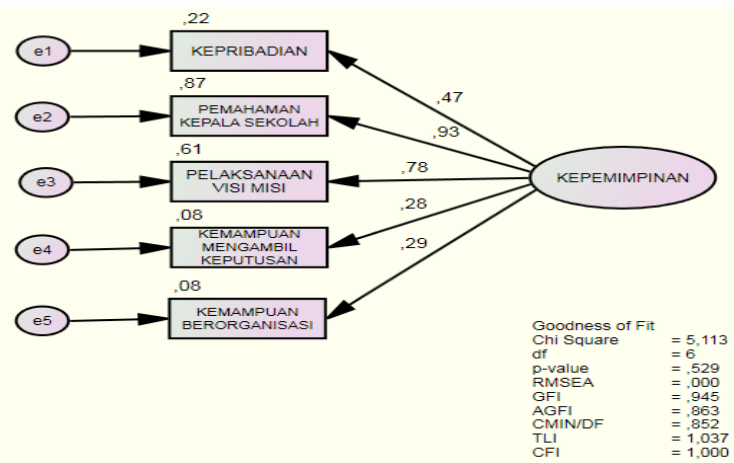

Gambar 2

Hasil Analisis Konfirmatori Variabel Kepemimpinan $\left(\mathrm{X}_{1}\right)$

Untuk melakukan analisis konfirmatori variabel kepemimpinan, uji dasar yang harus dilakukan yaitu dengan menguji kesesuaian model - Goodness of Fit Test, hasil pengujian kesesuaian model pada konfirmatori factor analisis disajikan dalam Tabel di bawah ini: 
Tabel 1

Hasil Pengujian Kelayakan Variabel Kepemimpinan $\left(X_{1}\right)$

\begin{tabular}{|l|l|l|l|}
\hline $\begin{array}{l}\text { Goodness of } \\
\text { Fit Indeks }\end{array}$ & $\begin{array}{l}\text { Cut off } \\
\text { Value }\end{array}$ & Hasil & $\begin{array}{l}\text { Evaluasi } \\
\text { Model }\end{array}$ \\
\hline Chi-Square & $\leq 11,07$ & 5,113 & Memenuhi \\
\hline DF & & 6 & \\
\hline P-Value & $\geq 0,05$ & 0,529 & Memenuhi \\
\hline RMSEA & $\leq 0,08$ & 0,000 & Memenuhi \\
\hline GFI & $\geq 0,90$ & 0,945 & Memenuhi \\
\hline AGFI & $\geq 0,90$ & 0,863 & $\begin{array}{l}\text { Tidak } \\
\text { Memenuhi }\end{array}$ \\
\hline CMIN/DF & $\leq 2,00$ & 0,852 & Memenuhi \\
\hline TLI & $\geq 0,95$ & 1,037 & Memenuhi \\
\hline CFI & $\geq 0,95$ & 1,000 & Memenuhi \\
\hline
\end{tabular}

Sumber: Data Primer Diolah, 2016

Dari Tabel di atas menunjukkan bahwa nilai Chi Square $=5,5113$ dengan tingkat signifikansi sebesar 11,07 demikian pula dengan nilai kelayakan yang lain yang memenuhi kriteria fit sehingga dapat disimpulkan bahwa tidak terdapat perbedaan antara matriks kovarians sample dengan matriks kovarians populasi yang diestimasi diterima yang berarti model adalah fit. Sehingga secara keseluruhan model dapat diterima untuk memberikan konfirmasi yang cukup untuk dapat diterimanya hipotesis unidimensionalitas bahwa kelima indicator yang digunakan dapat mencerminkan variabel laten yang dianalisis yaitu variable kepemimpinan.

\section{b. Analisis Konfirmatori Variabel Motivasi Kerja $\left(\mathbf{X}_{2}\right)$}

Analisis konfirmatori variabel motivasi kerja dilakukan untuk mengkonfirmasi apakah indikator yang diamati dapat mencerminkan faktor yang dianalisis yaitu variabel motivasi kerja. Adapun hasil analisis konfirmatori yang dilakukan terhadap variabel motivasi kerja diuraikan di bawah ini :

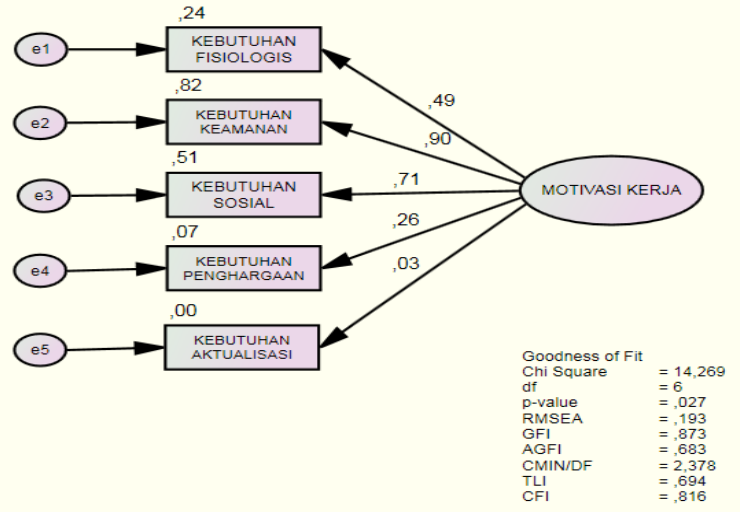

Gambar 3

Hasil Analisis Konfirmatori Variabel Motivasi Kerja $\left(\mathbf{X}_{2}\right)$

Untuk melakukan analisis konfirmatori variabel motivasi kerja, harus dilakukan pemenguji kesesuaian model - Goodness of Fit Test, hasil pengujian kesesuaian model pada konfirmatori factor analisis disajikan dalam Tabel di bawah ini :

Tabel 2

Hasil Pengujian Kelayakan Variabel Motivasi Kerja $\left(\mathrm{X}_{2}\right)$

\begin{tabular}{|l|l|l|l|}
\hline $\begin{array}{l}\text { Goodness of } \\
\text { Fit Indeks }\end{array}$ & $\begin{array}{l}\text { Cut off } \\
\text { Value }\end{array}$ & Hasil & $\begin{array}{l}\text { Evaluasi } \\
\text { Model }\end{array}$ \\
\hline Chi-Square & $\leq 11,07$ & 14,269 & $\begin{array}{l}\text { Tidak } \\
\text { memenuhi }\end{array}$ \\
\hline DF & & 6 & \\
\hline P-Value & $\geq 0,05$ & 0,027 & $\begin{array}{l}\text { Tidak } \\
\text { memenuhi }\end{array}$ \\
\hline RMSEA & $\leq 0,08$ & 0,193 & $\begin{array}{l}\text { Tidak } \\
\text { memenuhi }\end{array}$ \\
\hline GFI & $\geq 0,90$ & 0,873 & $\begin{array}{l}\text { Tidak } \\
\text { memenuhi }\end{array}$ \\
\hline AGFI & $\geq 0,90$ & 0,683 & $\begin{array}{l}\text { Tidak } \\
\text { memenuhi }\end{array}$ \\
\hline CMIN/DF & $\leq 2,00$ & 2,378 & $\begin{array}{l}\text { Tidak } \\
\text { memenuhi }\end{array}$ \\
\hline TLI & $\geq 0,95$ & 0,694 & $\begin{array}{l}\text { Tidak } \\
\text { memenuhi }\end{array}$ \\
\hline CFI & $\geq 0,95$ & 0,816 & $\begin{array}{l}\text { Tidak } \\
\text { memenuhi }\end{array}$ \\
\hline
\end{tabular}

Sumber: Data Primer Diolah, 2016

Dari Tabel di atas menunjukkan bahwa nilai Chi Square $=14,269$ dengan tingkat signifikansi sebesar 11,07 demikian pula dengan nilai 
kelayakan yang lain yang belum memenuhi kriteria fit sehingga dapat disimpulkan bahwa terdapat perbedaan antara matriks kovarians sample dengan matriks kovarians populasi yang diestimasi tidak diterima yang berarti model adalah belum fit.

\section{c. Analisis Konfirmatori Variabel Kompetensi $\left(\mathbf{X}_{\mathbf{3}}\right)$}

Analisis konfirmatori variabel kompetensi dilakukan untuk mengkonfirmasi apakah indikator yang diamati dapat mencerminkan faktor yang dianalisis yaitu variabel kompetensi. Adapun hasil analisis konfirmatori yang dilakukan terhadap variabel kompetensi diuraikan di bawah ini :

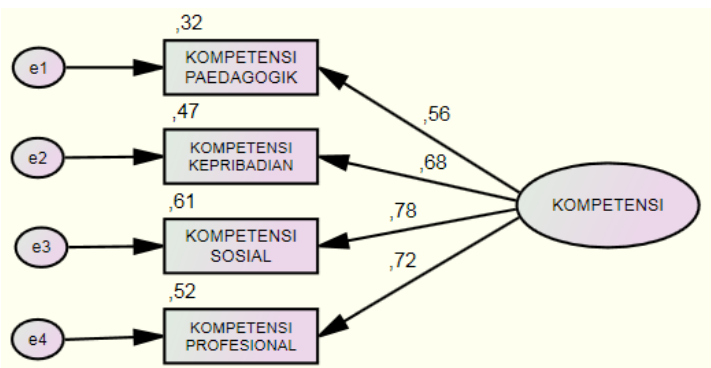

\section{Gambar 4 \\ Hasil Analisis Konfirmatori Variabel Kompetensi $\left(\mathbf{X}_{3}\right)$}

Untuk melakukan analisis konfirmatori variabel komptensi, uji dasar yang harus dilakukan yaitu dengan menguji kesesuaian model - Goodness of Fit Test, hasil pengujian kesesuaian model pada konfirmatori factor analisis disajikan dalam Tabel di bawah ini :
Tabel 3

Hasil Pengujian Kelayakan Variabel Kompetensi $\left(\mathrm{X}_{3}\right)$

\begin{tabular}{|l|l|l|l|}
\hline $\begin{array}{l}\text { Goodness of } \\
\text { Fit Indeks }\end{array}$ & $\begin{array}{l}\text { Cut off } \\
\text { Value }\end{array}$ & Hasil & $\begin{array}{l}\text { Evaluasi } \\
\text { Model }\end{array}$ \\
\hline Chi-Square & $\leq 7,81$ & 18,249 & $\begin{array}{l}\text { Tidak } \\
\text { memenuhi }\end{array}$ \\
\hline DF & $\geq 0,05$ & 0,000 & $\begin{array}{l}\text { Tidak } \\
\text { memenuhi }\end{array}$ \\
\hline P-Value & $\leq 0,08$ & 0,371 & $\begin{array}{l}\text { Tidak } \\
\text { memenuhi }\end{array}$ \\
\hline RMSEA & $\geq 0,90$ & 0,826 & $\begin{array}{l}\text { Tidak } \\
\text { memenuhi }\end{array}$ \\
\hline GFI & $\geq 0,90$ & 0,421 & $\begin{array}{l}\text { Tidak } \\
\text { memenuhi }\end{array}$ \\
\hline AGFI & $\leq 2,00$ & 6,083 & $\begin{array}{l}\text { Tidak } \\
\text { memenuhi }\end{array}$ \\
\hline CMIN/DF & $\geq 0,95$ & 0,605 & $\begin{array}{l}\text { Tidak } \\
\text { memenuhi }\end{array}$ \\
\hline TLI & $\geq 0,95$ & 0,802 & $\begin{array}{l}\text { Tidak } \\
\text { memenuhi }\end{array}$ \\
\hline CFI & &
\end{tabular}

Sumber: Data Primer Diolah, 2016

Dari Tabel 3 menunjukkan bahwa nilai Chi Square $=18,249$ dengan tingkat signifikansi sebesar 7,81 demikian pula dengan nilai kelayakan yang lain yang belum memenuhi kriteria fit sehingga dapat disimpulkan bahwa terdapat perbedaan antara matriks kovarians sample dengan matriks kovarians populasi yang diestimasi tidak diterima yang berarti model adalah belum fit.

\section{d. Analisis Konfirmatori Variabel Kinerja Guru ( $\left.\mathbf{Y}_{1}\right)$}

Analisis konfirmatori variabel kinerja guru dilakukan untuk mengkonfirmasi apakah indikator yang diamati dapat mencerminkan faktor yang dianalisis yaitu variabel kinerja guru. Adapun hasil analisis konfirmatori yang dilakukan terhadap variabel kinerja guru diuraikan di bawah ini : 


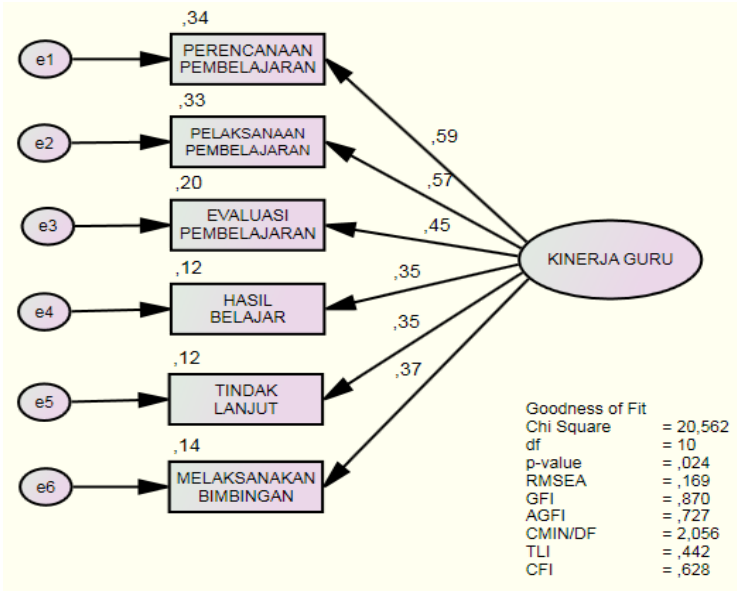

Gambar 5

Hasil Analisis Konfirmatori Variabel Kinerja Guru ( $\left.\mathbf{Y}_{1}\right)$

Untuk melakukan analisis konfirmatori variabel kinerja guru, uji dasar yang harus dilakukan yaitu dengan menguji kesesuaian model - Goodness of Fit Test, hasil pengujian kesesuaian model pada konfirmatori factor analisis disajikan dalam Tabel di bawah ini :

Tabel 6

Hasil Pengujian Kelayakan Variabel Kinerja Guru $\left(Y_{1}\right)$

\begin{tabular}{|l|l|l|l|}
\hline $\begin{array}{l}\text { Goodness of } \\
\text { Fit Indeks }\end{array}$ & $\begin{array}{l}\text { Cut off } \\
\text { Value }\end{array}$ & Hasil & $\begin{array}{l}\text { Evaluasi } \\
\text { Model }\end{array}$ \\
\hline Chi-Square & $\leq 18,31$ & 20,562 & $\begin{array}{l}\text { Tidak } \\
\text { memenuhi }\end{array}$ \\
\hline DF & $\geq 0,05$ & 0,024 & $\begin{array}{l}\text { Tidak } \\
\text { memenuhi }\end{array}$ \\
\hline P-Value & $\leq 0,08$ & 0,169 & $\begin{array}{l}\text { Tidak } \\
\text { memenuhi }\end{array}$ \\
\hline RMSEA & $\geq 0,90$ & 0,870 & $\begin{array}{l}\text { Tidak } \\
\text { memenuhi }\end{array}$ \\
\hline GFI & $\geq 0,90$ & 0,727 & $\begin{array}{l}\text { Tidak } \\
\text { memenuhi }\end{array}$ \\
\hline AGFI & $\leq 2,00$ & 2,056 & $\begin{array}{l}\text { Tidak } \\
\text { memenuhi }\end{array}$ \\
\hline CMIN/DF & $\geq 0,95$ & 0,442 & $\begin{array}{l}\text { Tidak } \\
\text { memenuhi }\end{array}$ \\
\hline TLI & $\geq 0,95$ & 0,628 & $\begin{array}{l}\text { Tidak } \\
\text { memenuhi }\end{array}$ \\
\hline CFI & & 10 &
\end{tabular}

Sumber: Data Primer Diolah, 2016
Dari Tabel di atas menunjukkan bahwa nilai $C h i$ Square $=20,562$ dengan tingkat signifikansi sebesar 18,31 demikian pula dengan nilai kelayakan yang lain yang belum memenuhi kriteria fit sehingga dapat disimpulkan bahwa terdapat perbedaan antara matriks kovarians sample dengan matriks kovarians populasi yang diestimasi diterima yang berarti model adalah belum fit. Sehingga secara keseluruhan model belum dapat diterima untuk memberikan konfirmasi yang cukup.

\section{Pengujian Hipotesis}

Hasil analisis SEM dari penelitian ini dijabarkan dalam langkah pengujian hipotesis sebagai berikut:

\section{a. Pengujian Hipotesis 1}

$\mathrm{H}_{1}$ : Terdapat pengaruh antara kepemimpinan, motivasi kerja dan komptensi terhadap kepuasan kerja guru SMK Muhammadiyah Bulakamba Kabupaten Brebes.

Adapun hasil analisis SEM yang dilakukan diuraikan dalam gambar di bawah ini :

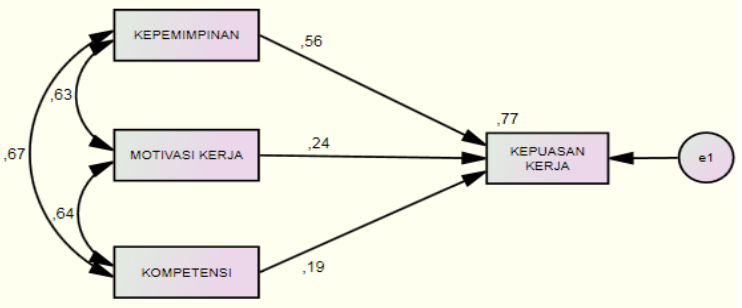

Gambar 6

Hasil Analisis Pengaruh Variabel

Kepemimpinan, Motivasi Kerja dan

Kompetensi terhadap Variabel Kepuasan Kerja

Pada gambar di atas dapat dijelaskan bahwa nilai koefisien regresi terstandar (beta) Kepemimpinan $\left(\mathrm{X}_{1}\right)$ terhadap Kepuasan Kerja Guru memperoleh nilai sebesar 0,56, Motivasi 
Kerja $\left(\mathrm{X}_{2}\right)$ terhadap Kepuasan Kerja Guru memperoleh nilai sebesar 0,24 dan Kompetensi $\left(\mathrm{X}_{3}\right)$ terhadap Kepuasan Kerja Guru memperoleh nilai sebesar 0,19 . Dari nilai ketiga koefisien ini dapat disimpulkan bahwa variable Kepemimpinan lebih penting dalam mempengaruhi Kepuasan Kerja Guru, dibandingkan dengan variabel Motivasi Kerja dan variabel Kompetensi.

Tabel 7

Variances: (Default model)

\begin{tabular}{|lrrrcl|}
\hline & Estimate & S. E. & C. R. & P & Label \\
\hline X1 & 46,548 & 10,822 & 4,301 & $* * *$ & par_7 \\
X2 & 64,879 & 15,084 & 4,301 & $* * *$ & par_8 \\
X3 & 68,436 & 15,911 & 4,301 & $* * *$ & par_9 \\
e1 & 5,288 & 1,229 & 4,301 & $* * *$ & par_10 \\
\hline
\end{tabular}

Pada tabel diatas dapat dilihat hasil p-value pada kolom $\mathrm{P}$ berupa tiga buah tanda asterisk $(* * *)$, yang berarti nilai p-value sanggat kecil $(<0,001)$, maka dengan demikian bahwa hipotesis yang menyatakan terdapat pengaruh antara Kepemimpinan, Motivasi Kerja dan Kompetensi terhadap Kepuasan Kerja Guru SMK. Muhammadiyah Bulakamba Kabupaten Brebes terbukti kebenaraanya.

\section{b. Pengujian Hipotesis 2}

$\mathrm{H}_{2}$ : Terdapat pengaruh antara Kepemimpinan, Motivasi Kerja dan Kompetensi terhadap Kinerja Guru SMK. Muhammadiyah Bulakamba Kabupaten Brebes.

Adapun hasil analisis SEM yang dilakukan diuraikan dalam gambar di bawah ini :

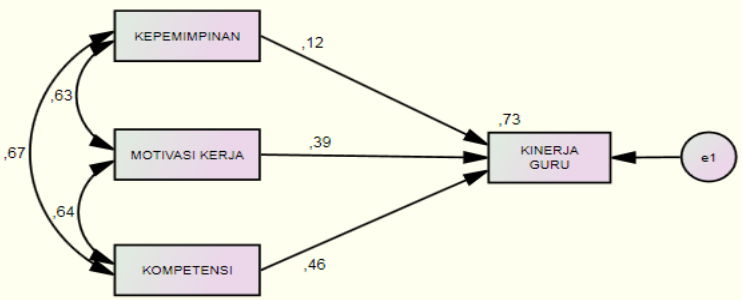

Gambar 7

Hasil Analisis Pengaruh Variabel

Kepemimpinan, Motivasi Kerja dan

Kompetensi terhadap Variabel Kinerja Guru

Pada gambar di atas dapat dijelaskan bahwa nilai koefisien regresi terstandar (beta) Kepemimpinan $\left(\mathrm{X}_{1}\right)$ terhadap Kinerja Guru memperoleh nilai sebesar 0,12 , Motivasi Kerja $\left(\mathrm{X}_{2}\right)$ terhadap Kinerja Guru memperoleh nilai sebesar 0,39 dan Kompetensi $\left(\mathrm{X}_{3}\right)$ terhadap Kinerja Guru memperoleh nilai sebesar 0,46. Dari nilai ketiga koefisien ini dapat disimpulkan bahwa variable Kompetensi lebih penting dalam mempengaruhi Kinerja Guru, dibandingkan dengan variabel Kepemimpinan dan Motivasi Kerja.

Tabel 8

Variances: (Default model)

\begin{tabular}{|l|rrrcc|}
\hline & \multicolumn{1}{|c}{ Estimate } & S. E. & C. R. & P & Label \\
\hline X1 & 46,548 & 10,822 & 4,301 & $* * *$ & par_7 \\
X2 & 64,879 & 15,084 & 4,301 & $* * *$ & par_8 \\
X3 & 68,436 & 15,911 & 4,301 & $* * *$ & par_9 \\
e1 & 10,705 & 2,489 & 4,301 & $* * *$ & par_10 \\
\hline
\end{tabular}

Pada tabel diatas dapat dilihat hasil p-value pada kolom $\mathrm{P}$ berupa tiga buah tanda asterisk $(* * *)$, yang berarti nilai $p$-value sanggat kecil $(<0,001)$, maka dengan demikian bahwa hipotesis yang menyatakan terdapat pengaruh antara Kepemimpinan, Motivasi Kerja dan Kompetensi terhadap Kinerja Guru SMK. Muhammadiyah Bulakamba Kabupaten Brebes terbukti kebenarannya. 


\section{c. Pengujian Hipotesis 3}

$\mathrm{H}_{3}$ : Terdapat pengaruh antara Kepuasan Kerja terhadap Kinerja Guru pada SMK. Muhammadiyah Bulakamba Kabupaten Brebes.

Adapun hasil analisis SEM yang dilakukan diuraikan dalam gambar di bawah ini :

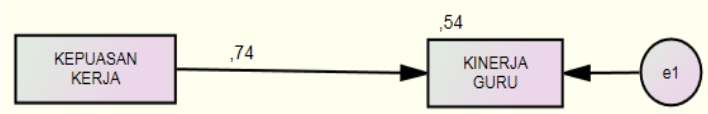

Gambar 8

Hasil Analisis Pengaruh Variabel Kepuasan Kerja terhadap Variabel Kinerja Guru

Pada gambar di atas dapat dijelaskan bahwa nilai koefisien regresi terstandar (beta) Kepuasan Kerja ( $\left.\mathrm{Y}_{1}\right)$ terhadap Kinerja Guru $\left(\mathrm{Y}_{2}\right)$ memperoleh nilai sebesar 0,74 .

Tabel 9

Variances: (Default model)

\begin{tabular}{|l|rrrrr|}
\hline & Estimate & $\begin{array}{c}\text { S. } \\
\text { E. }\end{array}$ & $\begin{array}{c}\text { C. } \\
\text { R. }\end{array}$ & P & Label \\
\hline y2 & 22,554 & 5,244 & 4,301 & $* * *$ & par_2 \\
e1 & 18,430 & 4,285 & 4,301 & $* * *$ & par_3 \\
\hline
\end{tabular}

Pada tabel diatas dapat dilihat hasil p-value pada kolom $\mathrm{P}$ berupa tiga buah tanda asterisk $(* * *)$, yang berarti nilai p-value sangat kecil $(<0,001)$, maka dengan demikian bahwa hipotesis yang menyatakan terdapat pengaruh antara Kepuasan Kerja terhadap Kinerja Guru SMK Muhammadiyah Bulakamba Kabupaten Brebes terbukti kebenarannya.

\section{d. Pengujian Hipotesis 4}

$\mathrm{H}_{4}$ : Terdapat pengaruh antara Kepemimpinan, Motivasi Kerja dan Kompetensi terhadap Kinerja Guru melalui Kepuasan Guru SMK. Muhammadiyah Bulakamba Kabupaten Brebes.
Adapun hasil analisis SEM yang dilakukan diuraikan dalam gambar di bawah ini :

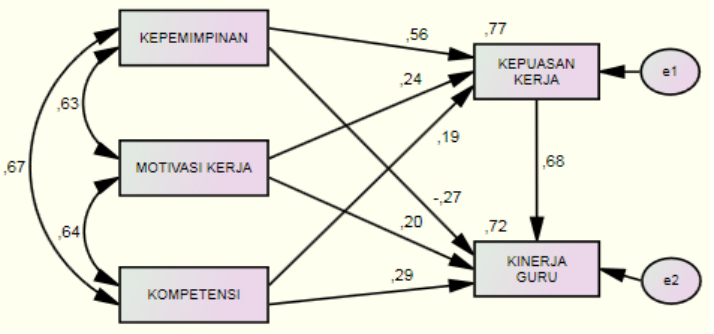

Gambar 9

Hasil Analisis Pengaruh Variabel Kepemimpinan, Motivasi Kerja dan Kompetensi terhadap Variabel Kinerja Guru melalui Kepuasan Kerja

Pada gambar di atas dapat dijelaskan bahwa nilai koefisien regresi terstandar (beta) Kepemimpinan $\left(\mathrm{X}_{1}\right)$, Motivasi Kerja $\left(\mathrm{X}_{2}\right)$ dan Kompetensi $\left(\mathrm{X}_{3}\right)$ terhadap Kinerja Guru $\left(\mathrm{Y}_{1}\right)$ melalui Kepuasan Kerja Guru memperoleh nilai sebesar 0,68.

Tabel 10

Variances: (Default model)

\begin{tabular}{|l|rrrrl|}
\hline & Estimate & S. E. & $\begin{array}{l}\text { C. } \\
\text { R. }\end{array}$ & P & Label \\
\hline X1 & 46,548 & 10,822 & 4,301 & $* * *$ & par_7 \\
X2 & 64,879 & 15,084 & 4,301 & $* * *$ & par_8 \\
X3 & 68,436 & 15,911 & 4,301 & $* * *$ & par_9 \\
e1 & 5,288 & 1,229 & 4,301 & $* * *$ & par_10 \\
e2 & 18,436 & 4,286 & 4,301 & $* * *$ & par_11 \\
\hline
\end{tabular}

Pada tabel diatas dapat dilihat hasil p-value pada kolom $\mathrm{P}$ berupa tiga buah tanda asterisk $(* * *)$, yang berarti nilai p-value sanggat kecil $(<0,001)$, maka dengan demikian bahwa hipotesis yang menyatakan terdapat pengaruh antara Kepemimpinan, Motivasi Kerja dan Kompetensi terhadap Kinerja Guru melalui Kepuasan Kerja Guru SMK. Muhammadiyah Bulakamba Kabupaten Brebes terbukti kebenarannya. 


\section{SIMPULAN}

Setelah dilakukan hasil analisis dan pengujian terhadap hipotesis yang diujikan, maka diambil kesimpulan atas hipotesis-hipotesis tersebut. Berikut ini kesimpulan penelitian atas empat hipotesis penelitian yang digunakan.

1. Kepemimpinan kepala SMK Muhammadiyah Bulakamba Brebes menunjukkan kepemimpinan yang tinggi dilihat dari rata-rata indeks variabel kepemimpinan yakni sebesar 83,1\%. Motivasi guru SMK Muhammadiyah Bulakamba Brebes menunjukkan motivasi yang tinggi dilihat dari rata-rata indeks variabel motivasi yakni sebesar $76,9 \%$. Kompetensi guru SMK Muhammadiyah Bulakamba Brebes menunjukkan kompetensi yang tinggi dilihat dari rata-rata indeks variabel kompetensi yakni sebesar 78,89\%. Kinerja guru SMK Muhammadiyah Bulakamba Brebes menunjukkan kinerja yang tinggi dilihat dari ratarata indeks variabel kinerja yakni sebesar 77,98\%. Kepuasan guru SMK Muhammadiyah Bulakamba Brebes menunjukkan kepuasan yang tinggi dilihat dari rata-rata indeks variabel kepuasan yakni sebesar $77,98 \%$.

2. Kepemimpinan, motivasi, dan kompetensi berpengaruh secara signifikan terhadap kepuasan guru SMK Muhammadiyah Bulakamba Brebes. Hal tersebut dibuktikan dari nilai koefisien regresi terstandar (beta) Kepemimpinan $\left(\mathrm{X}_{1}\right)$ terhadap Kepuasan Kerja Guru memperoleh nilai sebesar 0,56, Motivasi Kerja $\left(\mathrm{X}_{2}\right)$ terhadap Kepuasan Kerja Guru memperoleh nilai sebesar 0,24 dan Kompetensi $\left(\mathrm{X}_{3}\right)$ terhadap Kepuasan
Kerja Guru memperoleh nilai sebesar 0,19 .

3. Kepemimpinan, motivasi, dan kompetensi berpengaruh secara signifikan terhadap kinerja guru SMK Muhammadiyah Bulakamba Brebes. Hal tersebut dibuktikan dari nilai koefisien regresi terstandar (beta) Kepemimpinan $\left(\mathrm{X}_{1}\right)$ terhadap Kinerja Guru memperoleh nilai sebesar 0,12, Motivasi Kerja $\left(\mathrm{X}_{2}\right)$ terhadap Kinerja Guru memperoleh nilai sebesar 0,39 dan Kompetensi $\left(\mathrm{X}_{3}\right)$ terhadap Kinerja Guru memperoleh nilai sebesar 0,46.

4. Kepuasan berpengaruh secara signifikan terhadap kinerja guru SMK Muhammadiyah Bulakamba Brebes. Hal tersebut dibuktikan dari hasil pvalue berupa tiga buah tanda asterisk $(* * *)$, yang berarti nilai p-value sangat kecil $(<0,001)$, maka dengan demikian bahwa hipotesis yang menyatakan terdapat pengaruh antara Kepuasan Kerja terhadap Kinerja Guru SMK Muhammadiyah Bulakamba Kabupaten Brebes terbukti kebenarannya.

5. Kepemimpinan, motivasi, dan kompetensi berpengaruh secara signifikan terhadap kinerja melalui kepuasan guru SMK Muhammadiyah Bulakamba Brebes. Hal tersebut dibuktikan dari hasil p-value berupa tiga buah tanda asterisk $(* * *)$, yang berarti nilai $p$-value sanggat kecil $(<0,001)$, maka dengan demikian bahwa hipotesis yang menyatakan terdapat pengaruh antara Kepemimpinan, Motivasi Kerja dan Kompetensi terhadap Kinerja Guru melalui Kepuasan Kerja Guru SMK. Muhammadiyah Bulakamba Kabupaten Brebes terbukti kebenarannya. 


\section{DAFTAR PUSTAKA}

Arikunto, Suharsimi. 2009. Dasar-Dasar Evaluasi Pendidikan. Jakarta : Rineka Cipta.

Arikunto, Suharsimi. 2010. Prosedur Penelitian Pendekatan Praktek. Jakarta : Rineka Cipta.

Assad, Muhammad. 2005. Psikologi Industri. Jakarta : Liberty.

Bafadal, Ibrahim. 2003. Supervisi Pengajaran: Teori dan Aplikasinya dalam Membina Profesional Guru. Jakarta: Bumi Aksara.

Gomes, Faustino Cordoso. 2005. Manajemen Sumber Daya Manusia. Yogyakarta: Andi Offset

Hadi, Sutrisno. 2013. Metodologi Research Jilid 3. Yogyakarta: Andi

Hamzah, Uno. 2007. Profesi Kependidikan (Problema, Solusi dan Reformasi Pendidikan di Indonesia). Jakarta. PT Grafindo.

Handoko, T. Hani. 2003. Manajemen Personalia dan Sumber Daya Manusia. Yogyakarta : BPFE.

Hasibuan, Malayu S. P. 2011. Manajemen Sumber Daya Manusia. Jakarta: PT. Bumi Aksara.

Kunandar. 2012. Guru Profesional: Implementasi Kurikulum Tingkat Satuan Pendidikan Dan Sukses Dalam Sertifikasi Guru. Jakarta: Jakarta Pers.

Lumbanraja, Basaria. Pengaruh Gaya Kepemimpinan Dan Motivasi Kerja Terhadap Kinerja Guru Di SMP Negeri 1 Pandan. Online. www. pasca. ut. ac. id

Moekijat. 2010. Manajemen Sumber Daya Manusia. Bandung: Mandar Maju.

Mulyasa, Enco. 2004. Menjadi Kepala Sekolah Profesional Dalam Konteks Menyukseskan MBS dan KBK. Bandung: Remaja Rodakarya.

Remaja Rosdakarya.

Novitasari, Atik, dkk. 2013. Pengaruh Kepemimpinan Kepala Sekolah, Lingkungan Kerja, Pendidikan, Dan Pelatihan Terhadap Kinerja Guru. www. journal. unnes. ac. id

Nuraisyah, Siti. Pengaruh Kepemimpinan Kepala Sekolah, Budaya Organisasi Dan Motivasi Kerja Guru Terhadap Kinerja Guru Pada SMP Negeri Di Kecamatan Pandan Kabupaten Tapanuli Tengah Sumatera Utara. Online. www. pustaka. ut. ac. id

Pratiwi, Suryani Dewi. 2013. Pengaruh Motivasi Kerja, kepuasan Kerja, Kepemimpinan Kepala Sekolah Menurut persepsi Guru Dan Iklim Sekolah Terhadap Kinerja Guru Ekonomi SMP Negari Di Kabupaten Wonogiri. Online. www. jurnal. fkip. uns. ac. id

Raddana. 2013. Faktor-faktor Yang Mempengaruhi Kinerja Guru SMA Negeri Di Nusa Tenggara Barat. Jurnal Administrasi Publik Vol. 11 No. 2. 
Rivai, Veithzal. 2004. Performa Apraisal. Jakarta : Rajawali Press

Rosyada, Dede. 2009. Paradigma Pendidikan demokratis: Sebuah Model Pelibatan Masyarakat Dalam Penyelenggaraan Pendidikan. Jakarta: Prenada Media.

Saputra, Endri. 2013. Pengaruh Gaya Kepemimpinan Kepala Sekolah Dan Motivasi Kerja Guru Terhadap Kinerja Guru. Online. www. repository. edu. ac. id

Septiana Roslena, dkk. Pengaruh Kepemimpinan Kepala Sekolah Dan Motivasi Kerja Terhadap Kinerja Guru SMP Negeri Wonosari. Online. www. jurnal. fkip. uns. ac. id

Siagian, Sondang P. 2008. Teori Motivasi dan Aplikasinya. Jakarta : PT Rineka Cipta

Simamora, Henry. 2004. Manajemen Sumber Daya Manusia, Yogjakarta: BP LP3ES

Slamet, Achmad. 2007. Manajemen Sumber Daya Manusia, Semarang: Universitas Negeri Semarang.

Sudjana, Nana. 2005. Penilaian Hasil Proses Belajar Mengajar. Bandung: Remaja Rosdakarya.

Sudjana. 2005. Metoda Statistika. Bandung: Tarsito

Sugiyono. 2009. Statistika Untuk Penelitian. Bandung: Alfabeta.

Sukrisna, Hendra. 2013. Pengaruh Motivasi Kerja, Supervisi Kepala Sekolah, Dan Kesejahteraan Terhadap Kinerja Guru Sekolah Dasar Di Kecamatan Sukoharjo Kabupaten Sukoharjo. Oline. www. portalgaruda. org.

Tabrani. 2015. Pengaruh Kualitas Layanan, Harga, Relationship Marketing Terhadap Loyalitas Melalui Kepuasan Petani Rumput Laut Inti Plasma Tambak Aji Di Kabupaten Brebes. Disertasi. Universitas Merdeka Malang.

Terry, George R. Dan Leslie W. Rue. 2012. Dasar-dasar Manajemen. Jakarta: Bumi Aksara.

Usman, Moch. Uzer. 2005. Menjadi Guru Profesional. Bandung: Remaja Rosdakarya.

Wahjosumidjo. 2008. Kepemimpinan Kepala Sekolah. Jakarta : Raja Grafindo Persada.

Yuk1, G. A. 2005. Kepemimpinan Dalam Organisasi Terjemahan oleh Yusuf Udaya. Jakarta: Prehalindo. 